\title{
GATA6 regulates HNF4 and is required for differentiation of visceral endoderm in the mouse embryo
}

\author{
Edward E. Morrisey, ${ }^{1,2}$ Zhihua Tang $^{1,2}$ Kirsten Sigrist, ${ }^{1}$ Min Min Lu, ${ }^{1,2}$ Fang Jiang ${ }^{1}$ Hon S. Ip, ${ }^{1}$ \\ and Michael S. Parmacek ${ }^{1,2,3}$ \\ ${ }^{1}$ Department of M edicine, University of Chicago, Chicago, Illinois 60637 USA; ${ }^{2}$ Department of M edicine, University \\ of Pennsylvania, Philadel phia, Pennsylvania 19104 USA
}

\begin{abstract}
GATA6 belongs to a family of zinc finger transcription factors that play important roles in transolucing nuclear events that regulate cellular differentiation and embryonic mophogenesis in vertebrate species. To examine the function of GATA6 during embryonic development, gene targeting was used to generate GATA6-deficient (GATA $6^{-1}$ ) ES cells and mice harboring a null mutation in GATA6. Differentiated embryoid bodies derived from GA $\mathrm{TA}^{-1-}$ ES cells lack a covering layer of visceral endoderm and severely attenuate, or fail to express, genes encoding early and late endodermal markers, including HNF4, GATA4, $\alpha$-fetoprotein (AFP), and HNF33. Homozygous GAT A $6^{-1-}$ mice died between embryonic day (E) 6.5 and E7.5 and exhibited a specific defect in endoderm differentiation including severely down-regulated expression of GATA4 and absence of H NF4 gene expression. Moreover, widespread programmed cell death was observed within the embryonic ectoderm of GATA6-deficient embryos, a finding also observed in HNF4-deficient embryos. Consistent with these data, forced expression of GATA6 activated the H N F4 promoter in nonendodermal cells. Finally, to examine the function of GATA6 during later embryonic development, G AT A $6^{-1-}$-C57BL/ 6 chimeric mice were generated. lacZ-tagged G A T A $6^{-1-}$ ES cells contributed to all embryonic tissues with the exception of the endodermally derived bronchial epithelium. Taken together, these data suggest a model in which GATA6 lies upstream of HNF4 in a transcriptional cascade that regulates differentiation of the visceral endoderm. In addition, these data demonstrate that GATA6 is required for establishment of the endodermally derived bronchial epithelium.
\end{abstract}

[Key Words: Endoderm; transcription factor; HNF4; GATA]

Received June 4, 1998; revised version accepted September 16, 1998.

Endodermally derived cell lineages have evolved to facilitate filtration and exchange of nutrients across tissues during embryonic and postnatal devel opment. Each endodermally derived cell lineage subserves a unique function in developing vertebrates and these cell lineages can be distinguished morphologically and biochemically. Differentiation of endodermally derived cell lineages from the primitive endoderm occurs in a precise temporal and spatial pattern in vertebrate species. In the mouse, cells within the inner cell mass (ICM ) proliferate and segregate to form an outer layer of extraembryonic primitive endoderm that can be recognized as early as embryonic day (E) 4.0 shortly before implantation (for review, see Gardner 1983; Hogan et al . 1983). Production of injection chimeras strongly suggests that primitive endoderm cells col onize the extraembryonic visceral and parietal endoderm and do not contribute to the endodermal tissues of the fetus (Gardner 1982,1983). At the late

${ }^{3}$ Corresponding author.

E-MAIL parmacek@mail.med.upenn.edu; FAX (215) 349-8017. egg cylinder stage (E6.5), a population of cells within the epiblast migrates through the primitive streak and differentiates into the definitive embryonic endoderm. In addition, a small proportion of the definitive endoderm may be recruited directly from the overlying ectoderm (Tam and Beddington 1992). Immediately post-gastrulation (at E8.0), cells of the embryonic endoderm migrate through the embryo to line the primitive foregut, midgut, and hindgut cavities. The hepatic diverticulum arises from the junction of the primitive foregut and midgut at E8.5 and grows into the septum transversum. Finally, at E10.0, the tracheal diverticulum buds off the foregut and gives rise to the tracheal and bronchial epithelium, which can be recognized at E12.5.

A great deal has been learned about the developmental programs that control specification and differentiation of endoderm through the study of invertebrate species. Accumulating evidence suggests that a primordial function of transcription factors in the GATA family may be to specify endoderm and to activate the expression of endoderm-specific gene products (M acM orris et al. 1992; 
Reuter 1994; Stroeher et al. 1994; Rehorn et al. 1996; Zhu et al. 1997). In the Caenorhabditis el egans genome, an endoderm-determining genomic region (EDR) has been identified and is required zygotically to specify the $E$ cell fate (the endoderm in nematodes arises solely from the $\mathrm{E}$ blastomere). In $\mathrm{C}$. elegans embryos lacking the EDR, the $E$ cell gives rise to ectoderm and mesoderm instead of endoderm. The EDR mutant phenotype is rescued by forced expression of end-1, which encodes a single zinc finger GATA factor (Zhu et al. 1997). Similarly, in Drosophila, SERPEN T / ABF, a single zinc finger GATA factor, is expressed in a lineage-restricted fashion within the endoderm (Lin et al. 1994; Reuter 1994; Rehorn et al. 1996). In serpent mutants, the endodermally derived midgut is not made and a transformation from endoderm to ectoderm is observed in the midgut region (Rehorn et al. 1996).

In vertebrate species, members of the GATA family of type IV zinc finger transcription factors play key roles in transducing nuclear events that modulate cell lineage differentiation during vertebrate development (for review, see Orkin 1992; Simon 1995; Weiss and Orkin 1995). Six GATA factors have been identified in vertebrate species (Evans et al. 1988; T sai et al. 1989; Wilson et al . 1990; Ho et al. 1991; Dorfman et al. 1992; A rceci et al. 1993; Kelley et al. 1993; Laverriere et al. 1994; M orrisey et al. 1996, 1997). However, only members of the GATA4/GATA5/GATA 6 subfamily are expressed in the extraembryonic and embryonic endoderm during early development (Arceci et al. 1993; Laverriere et al. 1994; Morrisey et al. 1996, 1997). In the primitive streak mouse embryo, GATA4 and GATA 6 are coexpressed in the visceral and parietal endoderm (M orrisey et al. 1996). Subsequently, GATA4, GATA5, and GATA 6 are coexpressed in the embryonic heart and gut epithelium. However, coincident with formation of the embryonic lung bud, only GATA 6 is expressed in the endodermally derived bronchial epithelium (Morrisey et al. 1997). Recently, we reported that GATA4-deficient embryos display profound defects in ventral morphogenesis and heart tube formation. However, embryos harboring a null mutation in the gene encoding GATA4 contain intact yolk sacs that express high levels of the endodermal markers GATA6, HNF4, and HNF3 $\beta$ (Kuo et al. 1997; Molkentin et al. 1997). Thus, it remains unclear what role, if any, GATA factors play in development of the endoderm in vertebrate species.

In the studies described in this report, gene targeting was used to examine the function of GATA6 in differentiating ES cells and in the developing mouse. Differentiated embryoid bodies derived from GATA6 ${ }^{-1-}$ ES cells lack a covering layer of visceral endoderm and the expression of both early and late markers of visceral endoderm is severely down-regulated or abolished. GATA $6^{-1-}$ embryos die at the early primitive streak stage (between E6.5 and E7.5) and exhibit a speci fic block in endoderm differentiation including severely attenuated expression of GATA4 and absence of HNF4 gene expression. In addition, cell death is observed within the embryonic ectoderm in GATA $6^{-1-}$ embryos beginning at
E6.5. Consistent with these data, forced expression of GATA 6 transactivated the HNF4 promoter. Finally, we observed that GATA $6^{-1-}$ ES cells fail to contribute to the embryonic bronchial epithelium. Taken together, these data demonstrate that GATA 6 plays a critical role in differentiation of the visceral endoderm required for survival of the embryo past the early primitive streak stage. In addition, GATA 6 plays an important role in establishment of the endodermally derived bronchial epithelium.

\section{Results}

Targeted disruption of GATA 6 gene in ES cells

To produce a null mutation of the GATA6 gene, a targeting vector was constructed in which exons 4 and 5, encoding the amino- and carboxy-terminal zinc finger DNA-binding domain of the GATA6 protein, were re placed with a phosphoglycerokinase (PGK)-neomycin resistance (neo) cassette (Fig. 1A). The linearized targeting vector was electroporated into RW ES cells. Four of the 203 G418- and gancyclovir-resistant ES cell colonies screened were shown to be homologous recombinants by Southern blot analysis. Each of these GATA $6^{+1-}$ clones contained a single site of integration of the vector in the host genome as determined by Southern blot analyses performed with a neo probe (data not shown). To generate GATA6-deficient ES cells (GATA6 ${ }^{-1}$ ), independently derived GATA $6^{+/-}$ES cell lines were subjected to growth selection in high concentrations of G418 (Mortenson et al. 1992). Southern blot analyses performed on high concentration G418-resistant colonies served to identify 24 independent GATA $6^{-1-}$ clones.

To confirm that we had generated a null mutation with this targeting strategy, N orthern bl ot analyses were performed on RNA isolated from wild-type RW ES cells $\left(\right.$ GATA $\left.6^{++}\right)$, heterozygous ES cells (GATA $\left.6^{+/}\right)$and homozygous mutant ES cells (GATA $6^{-1}$ ) following their differentiation into embryoid bodies. High levels of GATA 6 mRNA were detected in embryoid bodies derived from the wild-type (wt) and heterozygous (GATA $6^{+-}$) ES cells after 12 days of differentiation (Fig. 1C). In contrast, GATA6 mRNA was not observed in differentiated embryoid bodies derived from GATA $^{-1-}$ ES cells (Fig. 1C). To confirm that GATA6 protein was not expressed in GATA $6^{-1-}$ ES cells, Western bl ot analyses were performed on whole cell extracts prepared from embryoid bodies derived from GATA $6^{+/+}$and $\mathrm{GATA} 6^{-1-}$ ES cells with GATA6-specific polyclonal antiserum. As expected, the polyclonal antiserum recognized a 48-kD protein (Fig. 1D, arrow) in the wild-type ES cells following 12 days of differentiation. In contrast, GATA 6 was not detected in whole cell extracts prepared from differentiated GATA $6^{-1-}$ ES cells (Fig. 1D). M oreover, in situ hybridization performed with a GATA6-specific riboprobe revealed that GATA 6 mRN A was not expressed in GATA6-deficient embryos (see Fig. 5D below). Taken together, these data confirmed that the targeted ES cells contain a null mutation in the GATA 6 gene. 
A

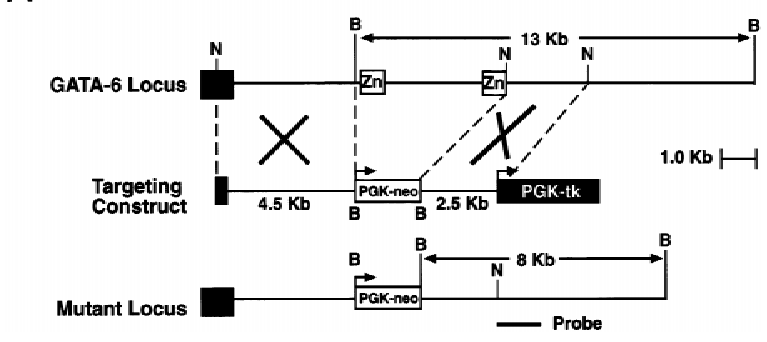

B

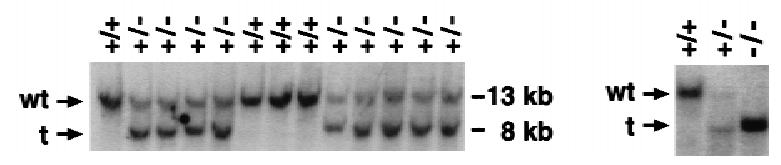

C

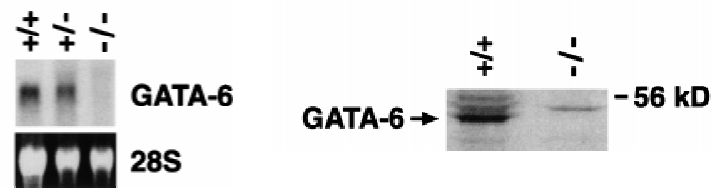

Figure 1. Targeted disruption of the GATA6 gene. (A) Schematic representation of the GATA6 targeting strategy. (Top) Partial restriction endonuclease map of the murine GATA 6 genomic locus. ( $)$ Exon 3; $(\bigcirc)$ exons 4 and 5. Restriction enzymes: ( $\mathrm{N}$ ot) N otl; ( $\mathrm{N} \mathrm{co}) \mathrm{N}$ col; (B) BamHI. (Middle) GATA6 targeting vector containing the neomycin-resistance (neo) and herpes simplex virus thymidine kinase (tk) genes under the control of the PGK promoter. (Bottom) Structure of the targeted GATA6 mutant allele. (B) (Left) Southern bl ot analysis of DN A prepared from the offspring of a GATA $6^{+-} \times \mathrm{GATA}^{+1-}$ mating. DNA was digested with BamHI and hybridized to the radiolabeled GATA 6 genomic probe shown in Fig. 1A. The positions of the wild-type $(13 \mathrm{~kb})$ and targeted $(8 \mathrm{~kb})$ allele are indicated with arrows at left. (Right) Southern blot analysis of DNA prepared from wild-type $(t+)$, heterozygous $(t-)$, and homozygous mutant $(-\rightarrow-$ ES cells demonstrating the wild-type (wt) and targeted (t) alleles. (C) (Top) N orthern blot analysis of GATA 6 gene expression in wild-type $(+t+)$, heterozygous $(+t-)$, and homozygous mutant $(-\dashv)$ ES cells. (Bottom) Equal loading and integrity of RNA was assessed by ethidium bromide staining of the $28 \mathrm{~S}$ RNA in the gel prior to transfer. (D) Western blot analysis of protein lysates prepared from wild-type $(+/+)$ ES cells and homozygous mutant GATA $6^{-1-}(-1-)$ ES cells foll owing 12 days of differentiation in vitro. Whole cell lysates prepared from differentiated wild-type and GATA $6^{-1-}$ ES cells were fractionated by SDS-PAGE, transferred to an Immobilon-P membrane, which was incubated with rabbit $\alpha$-mouse GATA 6 polyclonal antiserum, and visualized with goat anti-mouse horseradish peroxidase-coupled secondary antibody. The 56-kD marker is shown at right and the 48-kD band corresponding to GATA 6 is indicated with an arrow at left.

GATA6-deficient embryoid bodies exhibit a block in visceral endoderm differentiation

ES cells can be induced to aggregate and differentiate into cystic embryoid bodies (CEBs) that are covered by a layer of visceral endoderm (Doetschman et al. 1985; Soudais et al. 1995). Obvious differences were observed in the morphol ogy of embryoid bodies derived from control wild-type $\left(\mathrm{GATA}^{+++}\right)$ES cells and homozygous mutant $\left(\right.$ GATA $\left.6^{-1}\right)$ ES cells after 12 days of differentiation (Fig. $2 A$,B). Of note, CEBs from wild-type and heterozygous $\left(\right.$ GATA $6^{+1} \rightarrow$ ES cells were indistinguishable over the 12-day course of differentiation (data not shown). Consistent with previous reports (Soudais et al. 1995), CEBs derived from wild-type (wt) and heterozygous $\left(\right.$ GATA $\left.^{+/}\right)$ES cells were cystic structures covered with a smooth layer of visceral endoderm (Fig. 2A,C). Crosssections through embedded CEBs revealed that the visceral endoderm readily absorbed toluidine blue (Fig. 2C). Electron microscopic analysis confirmed that the covering layer of visceral endoderm contai ned a characteristic brush border with microvilli and numerous phagocytic vacuoles (Fig. 2E). In contrast, embryoid bodies derived from GATA $6^{-1-}$ ES cells were smaller and exhibited an irregular cobble-stoned surface (Fig. 2B). Cross-sections through embedded GATA $6^{-1-}$ mutant embryoid bodies revealed that they were relatively solid with well-orga-
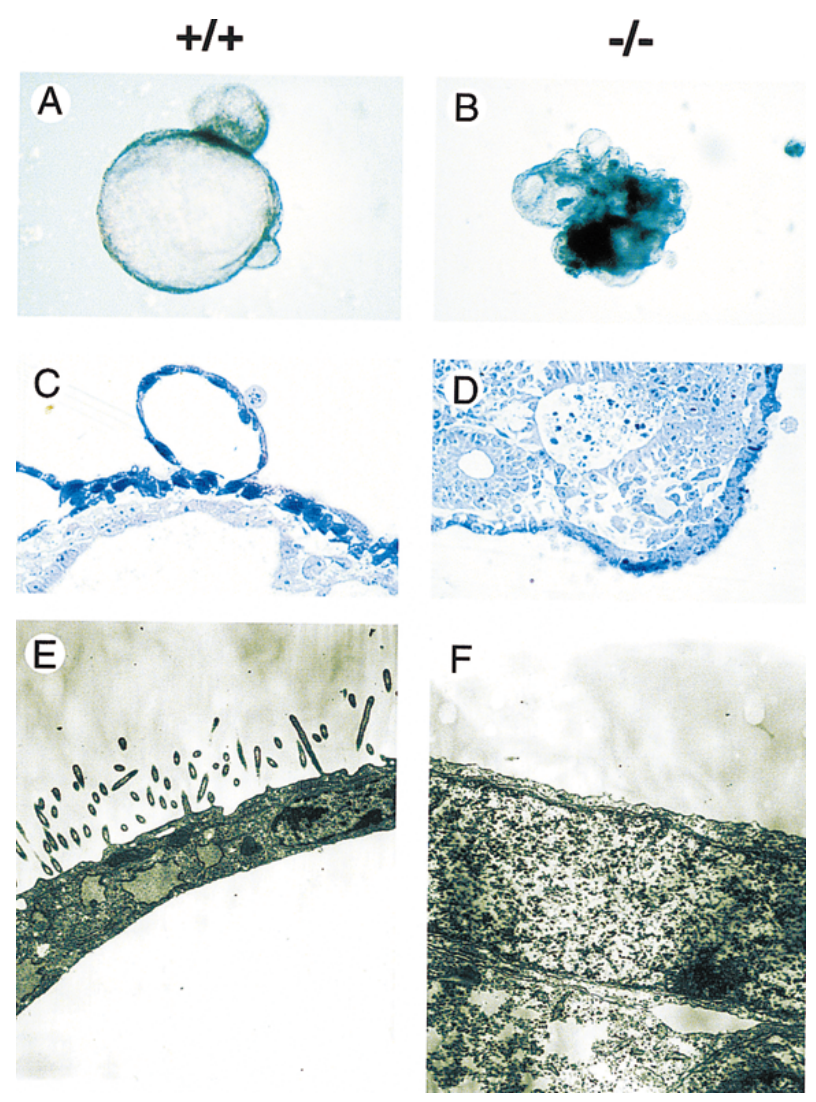

Figure 2. Morphology and ultrastructure of wild-type and GATA $6^{-1-}$ embryoid bodies following 12 days of differentiation in vitro. $(A, B)$ Gross appearance of wild-type $(+H)(A)$ and homozygous mutant $(-t \rightarrow$ (B) embryoid bodies. Magnification, $40 \times(C, D)$ Toluidine blue-stained $1 \mu \mathrm{m}$ cross-sections of differentiated wild-type (C) and GATA $6^{-1-}$ mutant (D) embryoid bodies. Magnification, $100 \times(E, F)$ Representative electron microscopic analysis of the surface of differentiated embryoid bodies derived from wild-type ES cells (E) and GATA $6^{-1-}$ ES cells (F). Magnification, 10,000x 
nized interior structures (Fig. 2D). In addition, cells covering the surface of GATA $6^{-1-}$ embryoid bodies were relatively large, cuboidal, and lacked phagocytic vacuoles (Fig. 2D). The vast majority of these cells were not stained dark blue with toluidine blue (Fig. 2D). Ultrastructurally, the surface of GATA6-deficient embryoid bodies contained relatively undifferentiated cells that lacked microvilli and phagocytic vacuoles and did not phenotypically resemble visceral endoderm (Fig. 2F).

To determine whether embryoid bodies derived from GATA $6^{-1-}$ ES cells expressed genes encoding markers of the visceral endoderm, $\mathrm{N}$ orthern bl ot anal yses were performed with RN A prepared from differentiated embryoid bodies derived from GATA $6^{+++}$and GATA $6^{-1-}$ ES cells. Abundant induction of genes encoding endodermal markers, including $\alpha$-fetoprotein (AFP), HN F3 $\beta, \mathrm{HNF}$, and GATA4, was observed in embryoid bodies beginning 4 days after induction of differentiation with levels of gene expression increasing over the 12-day course of differentiation (Fig. 3, lanes 1-6). In contrast, AFP, HNF4, and GATA4 gene expression was not induced in differentiated embryoid bodies derived from $\mathrm{GATA}^{-1-} \mathrm{ES}$ cells, whereas a small, but detectable, induction of HNF3 $\beta$ mRN A was observed in these cells (Fig. 3, lanes 7-12). Of note, HNF3 $\beta$ is expressed in both endoderm and the notochord floorplate of the developing neural tube (Lai et al. 1993; Sasaki and Hogan 1994; Weinstein et al. 1994). The fail ure of GATA $6^{-1-}$ embryoid bodies to express genes encoding markers of the endodermal lineage(s) was observed in multiple independent GATA $6^{-1-}$ ES cell clones and during multiple rounds of differentiation. Taken together, these data demonstrate that embryoid bodies derived from GATA $6^{-1-}$ ES cells exhibit a profound defect in endoderm differentiation.

\section{Generation of GATA6-deficient embryos}

Four independently derived GATA $6^{+1-E S}$ cell lines were used to generate chimeric mice, and these chimeric mice were crossed to $\mathrm{C} 57 \mathrm{BL} / 6$ mice to transmit the targeted

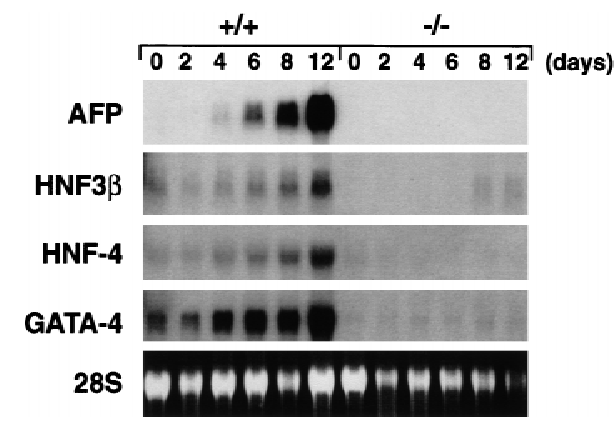

Figure 3. Northern blot analysis of endodermal markers in wild-type and GATA6 null embryoid bodies. Northern blots were prepared with RNA harvested from wild-type $(+/+)$ and GATA6 null $(-\rightarrow$ ES cells over a 12-day course of differentiation and were hybridized with radiolabeled $\alpha$-fetoprotein (AFP), HNF3 $\beta$, HN F4, or GATA4 probes. (Bottom) The 28S RN A band on the ethidium-stained gel prior to membrane transfer of RNA.
Table 1. Genotype of offspring from GATA $-6^{+/-} \times$GATA $-6^{+1-}$ matings

\begin{tabular}{|c|c|c|c|c|}
\hline Age & $H+$ & $H-$ & $-1-$ & Resorbed \\
\hline E6.5 & \multicolumn{2}{|c|}{$26^{a}$} & 10 & 1 \\
\hline E7.5 & \multicolumn{2}{|c|}{$36^{a}$} & 0 & 11 \\
\hline E8.5 & \multicolumn{2}{|c|}{$38^{a}$} & 0 & 11 \\
\hline Newborn & 75 (35\%) & $137(65 \%)$ & 0 & none \\
\hline
\end{tabular}

aGenotype was determined by in situ hydridization that does not distinguish between $+/$ and $+/$-genotypes.

allele through the germ line as determined by Southern blot analysis (Fig. 1B). Heterozygous GATA $6^{+/-}$mice were phenotypically normal and fertile. These mice were outbred to the BL/ 6 and CD-1 background to produce heterozygotes that were intercrossed to generate homozygous GATA $6^{-1-}$ mice. As shown in Figure 1B and Table 1, among 212 live-born offspring from GATA $6^{+-} \times \mathrm{GATA}^{+/-}$matings, no homozygous GATA $6^{-1-}$ live-born offspring were obtained. In contrast, $137(65 \%)$ heterozygous (GATA $6^{+1} \rightarrow$ and $75(35 \%)$ homozygous wild-type (GATA $\left.6^{+/}\right)$offspring were identified. To determine the date of embryonic death, embryos were microdissected from GATA $6^{+1-} \times \mathrm{GATA}^{+1-}$ matings at different stages of gestation and were genotyped by either Southern blot (after E8.5) or in situ hybridization (prior to E8.5) analysis. GATA $6^{-1-}$ embryos were not observed after E7.5, whereas the expected M endelian ratio was observed at E6.5 (Table 1). Thus, GATA6-deficient embryos died between E6.5 (the late egg cylinder stage) and E7.5 (the primitive streak stage) of mouse embryonic devel opment.

Because GATA6-deficient embryos died between E6.5 and E7.5, it was of interest to determine the precise temporal and spatial pattern(s) of GATA4 and GATA 6 gene expression during early embryonic development. Therefore, in situ hybridization analyses were performed on post-implantation mouse embryos utilizing GATA4and GATA6-specific riboprobes. Low level GATA4 gene expression was detected in E5.5 embryos exclusively within the visceral (VE) and parietal (PE) endoderm (Fig. 4B). In contrast, in E5.5 embryos, no differences were detected between the patterns of the hybridization observed with the antisense and control sense GATA6 riboprobes (Fig. 4C and data not shown). At E6.5, the genes encoding GATA4 and GATA6 were coexpressed within the yolk sac endoderm (Fig. 4E,F). High power views demonstrate hybridization of the GATA4 and GATA6 antisense riboprobes to both VE and PE (Fig. 4F). Hybridization of the control sense GATA4 and GATA6 riboprobes to adjacent sections was not observed. Thus, at the level of sensitivity afforded by these analyses, GATA-4 is expressed at least $12-24 \mathrm{hr}$ prior to the expression of GATA6 in the extra-embryonic VE and PE. Moreover, the lethality observed in GATA6deficient embryos occurs coincident with, or shortly after, the initiation of GATA6 gene expression in the advanced egg cylinder/early primitive streak mouse embryo. 


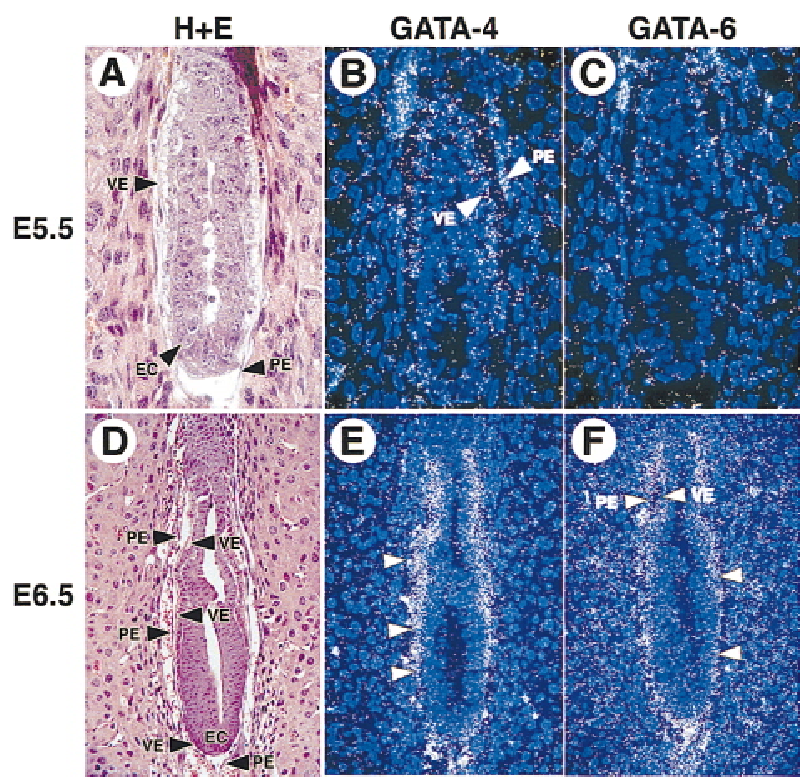

Figure 4. Expression of the GATA4 and GATA6 genes in the postimplantation mouse embryo. Histological and in situ hybridization analyses performed on E5.5 (A-C) and E6.5 (D-F) murine embryos. (A) A hematoxylin and eosin-stained section through the E5.5 embryo. (B) Hybridization of the GATA4 antisense riboprobe to yolk sac visceral endoderm (VE) and parietal endoderm (PE) of E5.5 embryos. (C) Hybridization of the antisense GATA 6 riboprobe to the E5.5 embryo. (D) A hemotoxylin and eosin-stained section through the E6.5 embryo. (VE) Visceral endoderm, (PE) parietal endoderm, (EC) embryonic ectoderm. (E) Hybridization of the GATA4 (E) and GATA6 (F) antisense riboprobe to E6.5 embryos.

\section{GATA $6^{-1-}$ embryos exhibit a specific defect in early endoderm differentiation}

The phenotype of differentiated embryoid bodies derived from GATA $6^{-1-}$ ES cells suggested that GATA-6 might play an important role in the specification and/or differentiation of the extra-embryonic or embryonic endoderm. In E6.5 wild-type and heterozygous control embryos, a single layer of VE and PE endoderm was observed (Fig. 5A). Cells of the extra-embryonic region (X$V E)$ were cuboidal, or columnar, with large numbers of apical vacuoles (Fig. 5A). In contrast, the visceral endoderm at the embryonic pole (E-VE) was squamous in morphology (Fig. 5A). In addition, several layers of embryonic ectoderm $(E C)$ were visualized within the epiblast (Fig. 5A). Mutant E6.5 GATA $6^{-1-}$ embryos were consistently smaller (10\%-20\%) than their heterozygous and wild-type littermates (Fig. 5, cf. A and B). These embryos possessed an intact layer of extra-embryonic (X$\mathrm{VE}$ ) and embryonic (E-VE) visceral endoderm, suggesting that endoderm is specified correctly in GATA6-deficient embryos (Fig. 5B). At E7.0, GATA $6^{-1-}$ embryos could be detected, but were severely growth retarded compared with their wild-type littermates (Fig. 6, cf. A and B). Whereas E7.0 null embryos contained VE and PE, there was a dramatic reduction in size of the epiblast with frequent pyknotic nuclei observed within the embryonic ectoderm (EC). By E7.5, all GATA6 $6^{-1-}$ embryos were either resorbed, or undergoing resorption (T able 1 ).

To determine whether GATA6-deficient embryos express genes encoding early endodermal markers, in situ hybridization analyses were performed on staged E6.5 GATA $6^{+/+}$control embryos and GATA $6^{-1-}$ mutant embryos. As expected, GATA6 mRN A was detected exclusively within the VE and PE of control embryos (Fig. 5C) but was undetectable in the VE or PE of GATA $6^{-1-} \mathrm{em}$ bryos (Fig. 5D). Consistent with previous reports (M orrisey et al. 1996; Kuo et al. 1997), GATA 4 was expressed in the VE and PE (arrowheads) of control embryos (Fig. 5E). In contrast, GATA4 gene expression (arrowheads) was detectable, but severely attenuated, in the VE and PE of GATA6-deficient embryos (Fig. 5F). HNF4 is a zinc finger transcription factor in the steroid hormone recep-

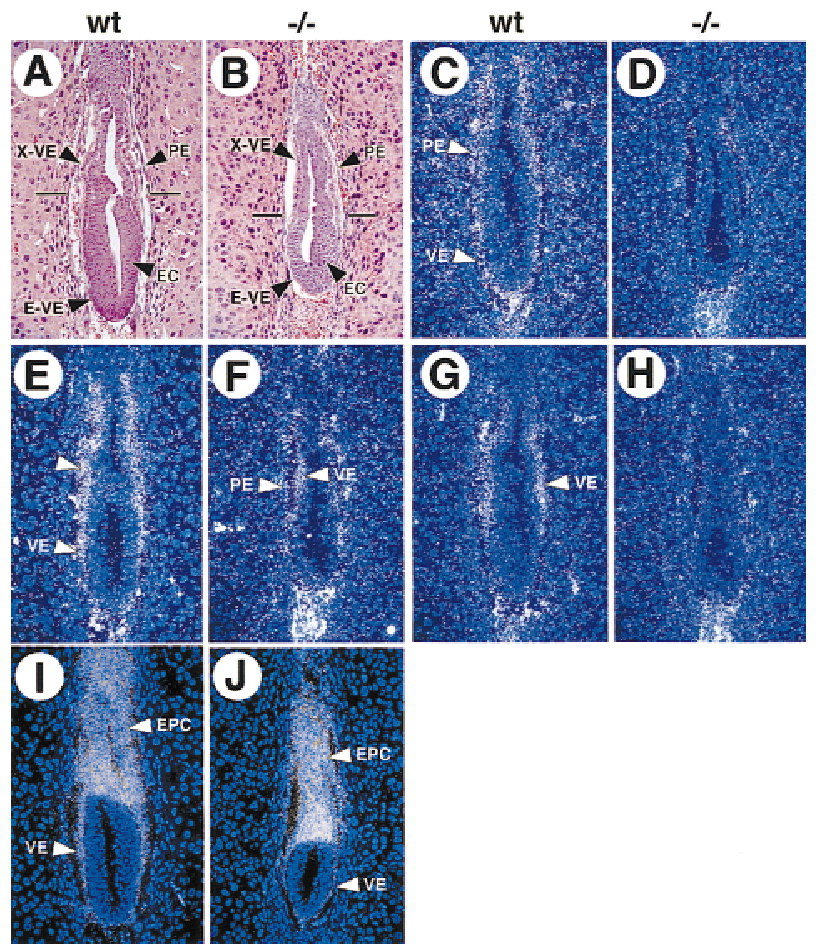

Figure 5. Expression of endodermal markers in wild-type and GATA $^{-1-}$ mutant E6.5 embryos. Histological and in situ hybridization analyses performed on wild-type (wt) and GATA $6^{-1-}$ $(-\rightarrow \rightarrow$ mutant E6.5 embryos. (A,B) A hematoxylin and eosinstained section of E6.5 wild-type (A) and GATA $6^{-1-}(B)$ embryos. $(\mathrm{X}-\mathrm{VE})$ Visceral endoderm at the extra-embryonic pole, (E-VE) visceral endoderm at the embryonic pole of the embryo, (PE) parietal endoderm, embryonic ectoderm (EC). (C,D) In situ hybridization performed with a radiolabeled GATA6 antisense riboprobe on a wild-type (C) and GATA $6^{-1-}$ (D) embryo. (E,F) In situ hybridization performed with a radiolabeled GATA4 antisense riboprobe on a wild-type (E) and GATA $6^{-1-}(D)$ embryo. $(\mathrm{G}, \mathrm{H})$ In situ hybridization performed with a radi ol abel ed HNF4 antisense riboprobe on a wild-type $(\mathrm{G})$ and $\mathrm{GATA} 6^{-1-}(\mathrm{H})$ embryo. (Arrowheads) Extraembryonic VE. $(I, J)$ In situ hybridization performed with a radiolabeled Pem antisense riboprobe in wild-type (I) and GATA $6^{-1-}(\mathrm{J})$ embryos. (EPC) Ectoplacental cone, (VE) proximal and distal visceral endoderm. 
tor superfamily that is expressed exclusively within the extra-embryonic endoderm at E6.5 (Sladek et al. 1990; Duncan et al. 1994). Although HNF4 mRNA (white arrowhead) was detected within the extra-embryonic VE of control embryos (Fig. 5G), at the level of sensitivity afforded by these analyses, the gene encoding HNF4 was not expressed in GATA6 ${ }^{-1-}$ embryos (Fig. 5H). In contrast, expression of Pem, a homeobox gene expressed in the proximal and distal VE, PE, and ectoplacental cone (EPC) at E6.5 (Lin et al. 1994), was expressed at comparable levels in control and GATA $6^{-1-}$ mutant embryos (Fig. 5I,J). Hybridization of control GATA6, GATA4, HNF4, and Pem sense riboprobes was not observed to adjacent sections of either wild-type or GATA6-deficient embryos (data not shown).

To confirm that the defect in expression of endodermal markers did not reflect a generalized down-regulation of gene expression throughout the embryo, the expression of genes that are expressed within the embryonic ectoderm was al so examined. Otx2 is a homeobox gene that is one of the earliest markers of the ectoderm in vertebrate species (Simeone et al . 1992). An Otx2 antisense riboprobe hybridized to the embryonic ectoderm (arrowheads) of wild-type (GATA $6^{++}$) and GATA6 $6^{-1-}$ embryos (Fig. 6C,D). Similarly, ENC1, which encodes a Kelch-related protein that is an early marker of the neuroectoderm within the epi blast (Hernandez et al. 1997), was expressed in both wild-type and GATA $6^{-1-}$ mutant embryos (Fig. 6E,F).

Cell death appears in the embryonic ectoderm of GATA6-deficient embryos

To determine whether the embryonic lethal ity observed in GATA 6-deficient embryos was related to programmed cell death, the TUN EL (TdT-mediated dUTP-biotin nick end labeling) reaction was performed on sections through E6.5 and E7.0 wild-type and GATA $6^{-1-}$ mutant embryos. In all GATA 6 mutant embryos examined there was an increase in TUN EL-positive, brown-stained nuclei (black arrowheads) in the embryonic ectoderm compared with wild-type E6.5 or E7.0 embryos (Fig. 7, cf. C and D). In addition, rare TUN EL-positive cells were observed within the PE of GATA6 ${ }^{-1-}$ embryos (Fig. 7D, blue arrowhead). Of note, this pattern of cell death within the embryonic ectoderm closely resembled that demonstrated previously in embryos harboring a null mutation in HNF4 (Chen et al. 1994).

GATA6 activates transcription of the HNF4 promoter in nonendodermal cells

A nalysis of the phenotype of differentiated GATA $6^{-1-}$ ES cells and GATA6-deficient embryos suggested that HNF4 might be a bona fide transcriptional target of GATA6 within the visceral endoderm. To determine whether forced expression of GATA 6 can activate the HNF4 promoter, mesodermally derived NIH-3T 3 cells were cotransfected with a luciferase reporter plasmid

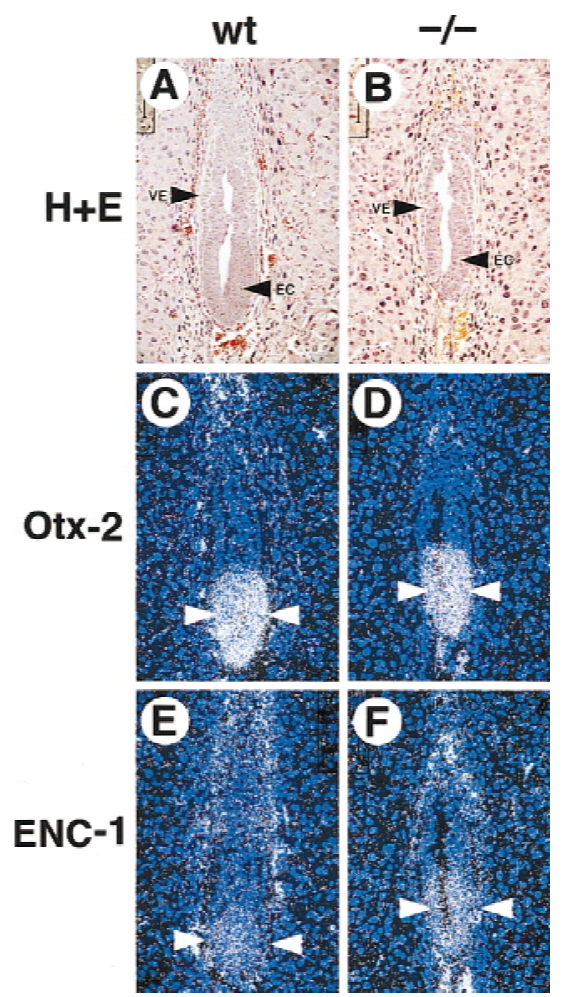

Figure 6. Expression of ectodermal markers in wild-type and GATA $6^{-1-}$ mutant E6.5 embryos. Histological and in situ hybridization analysis performed on wild-type (wt) and GATA $6^{-1-}$ $(-1 \rightarrow$ mutant E6.5 embryos. (A,B) Hematoxylin and eosinstained section of an E6.5 wild-type (A) and GATA $6^{-1-}(B)$ embryo. (VE) Visceral endoderm, (EC) embryonic ectoderm. (C,D) In situ hybridization performed with an Otx2 antisense riboprobe on the wild-type (C) and GATA $6^{-1-}$ (D) embryos. (Arrowheads) Hybridization signal. (E,F) In situ hybridization was performed with an ENC1 antisense riboprobe on the wild-type (E) and GATA6 ${ }^{-1-}$ (F) mutant embryos. (Arrowheads) Hybridization. Of note, epifluorescence is also observed in red blood cells within the yolk sac cavity. Magnification, 40x

containing the murine HNF4 promoter (pHNF4Pr.luc) (Taraviras et al. 1994) and the pcDN A G 6 expression vector encoding the murine GATA6 protein (Fig. 8). As anticipated, the pHN F4Pr.luc reporter plasmid was not activated by the control pcDNA3 eukaryotic expression plasmid (Fig. 8, lane 1). However, cotransfection of the pH N F4Pr.luc reporter plasmid with increasing amounts of the pcDNAG6 expression plasmid resulted in a stepwise increase in luciferase activity up to 60-fold above background levels (Fig. 8, lanes 2-4). Thus, GATA6 can transactivate the HNF4 promoter in nonendodermal cells.

GATA $6^{-1-}$ ES cells fail to contribute to the endodermally derived bronchial epithelium

The early lethality observed in GATA6 null embryos precluded assessment of the function of GATA 6 within other tissues in which the gene is expressed. To deter- 


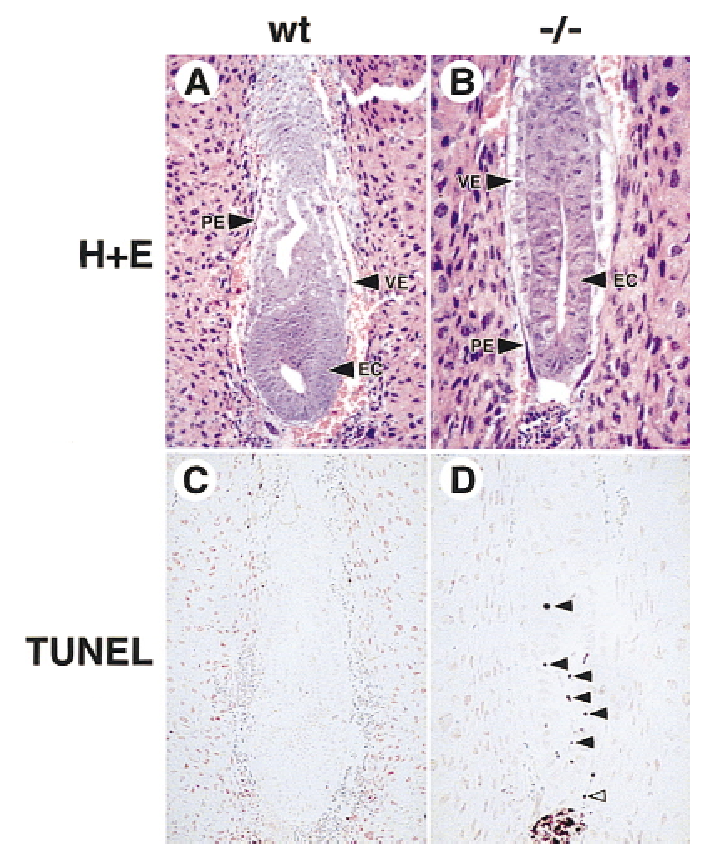

Figure 7. Cell death is observed in E7.0 GATA $6^{-1-}$ embryos. $(A, B)$ Histological sections of E7.0 wild-type (wt) (A) and GATA $6^{-1-}(-1 \rightarrow$ (B) embryos. (VE) Visceral endoderm, (PE) parietal endoderm. (C,D) E7.0 wild-type (C) and GATA $6^{-1-}$ mutant (D) embryos were subjected to the TUNEL reaction. Brownstained nuclei indicate end incorporation in DNA. Rare TUNEL-positive nuclei were observed in red blood cells within the yolk sac cavity in wild-type embryos (C). In contrast, multiple TUN EL-positive nuclei (black arrowheads) were observed within the embryonic ectoderm of E7.0 GATA $6^{-1-}$ mutant embryos (D). In addition, an occasional TUN EL-positive cell (blue arrowhead) was observed within the parietal endoderm of GATA $6^{-1-}$ mutant embryos.

mine the capacity of homozygous GATA6 $6^{-1-E S}$ cells to contri bute to other tissues during later embryonic development, lacZ-tagged GATA $6^{-1-}$ ES cells were injected into C57BL/ 6 blastocysts and GATA $6^{-1-}-\mathrm{C} 57 \mathrm{BL} / 6$ chimeric embryos were produced (Fig. 9A). At E10.5, GATA 6 is expressed within the primitive heart and the endodermally derived gut epithelium. In E10.5 chimeric embryos, blue-stained GATA $6^{-1-}$ cells contributed to most tissues including the neural tube (nt), somites (s), primitive atria (a) and ventricles (v), mesenchyme, body wall, and the primitive gut epithelium (Fig. 9B, arrow).

At E12.5, coincident with formation of the primitive lung bud, GATA 6 is the only member of the GATA family expressed in the endodermal ly derived bronchial epithelium (Fig. 9C). Remarkably, in multiple independent E13.5 chimeric embryos, lacZ ${ }^{+}-$GATA $^{-1-}$ cells were never observed within the bronchial epithel ium (Fig. 9D, $\mathrm{E}$, arrowheads). In contrast, lacZ-tagged GATA $6^{-1}$ cells did contribute to the pulmonary mesenchyme in these embryos (Fig. 9D,E). M oreover, the lacZ $Z^{+}$GATA $6^{-1-}$ ES cells contributed to other endodermally derived cell lineages in these embryos (data not shown). Of note, in control GATA6 $6^{+1-}$-C57BL/ 6 chimeric embryos, hetero- zygous lacZ-tagged GATA $6^{+/}$ES cells participated in formation of the embryonic bronchial epithelium (Fig. 9F). Thus, these data confirm that a cell intrinsic defect exists in the capacity of GATA $6^{-1-}$ ES cells to contribute to the bronchial epithelium. These data suggest that GATA 6 plays an important role in establishing this endodermally derived cell lineage.

\section{Discussion}

The function of GATA 6 in the late egg cylinder/ early primitive streak embryo

We used gene targeting to examine the function of the GATA 6 transcription factor during differentiation of ES cells and in the developing mouse. The data presented include the first conclusive evidence that a member of the GATA4/GATA5/GATA 6 subfamily is required for differentiation of VE in vivo. We observed that differentiated GATA6 $6^{-1-}$ mutant embryoid bodies do not develop $V E$ and fail to induce expression of genes encoding endodermal markers including GATA4, HNF4, HNF3 $\beta$, and AFP. More importantly, GATA6 null embryos demonstrated a specific block in endoderm differentiation including attenuated expression of GATA4 and absence of HNF4 gene expression. The defect observed within GATA6-deficient embryos appears to represent a specific block in the transcriptional program controlling endo-

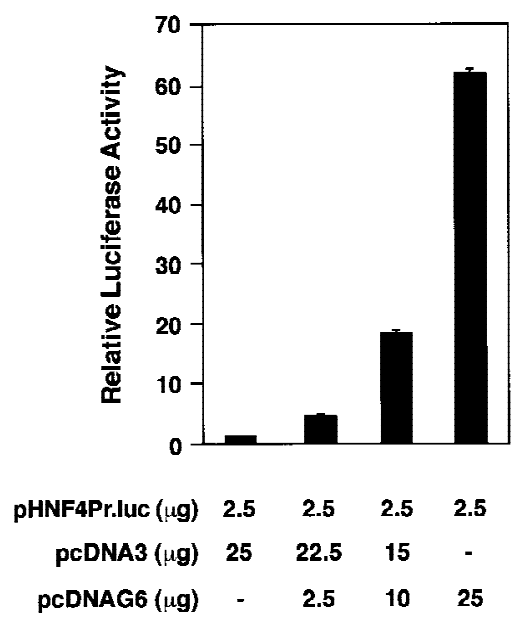

Figure 8. GATA6-modulated transactivation of the HNF4 promoter in NIH-3T 3 cells. NIH-3T 3 cells were transfected with $2.5 \mu \mathrm{g}$ of the luciferase reporter plasmid (pcHN F4Pr.luc) containing the murine HNF4 promoter and varying amounts $(\mu \mathrm{g})$ of an expression plasmid encoding GATA 6 (pcDN AG6) or the control plasmid (pcDNA3). All transfection mixtures also contained $1 \mu \mathrm{g}$ of the pMSV $\beta$ gal reference plasmid. Forty-eight hours after transfection, luciferase and $\beta$-gal actosi dase activities were determined. Luciferase activities corrected for differences in transfection efficiencies were normalized to luciferase activity obtained following transfection of the pHN F4Pr.luc plasmid with the pCDNA3 control plasmid. The data are presented as relative luciferase activities \pm S.E.M. The mean absolute light units obtained following transfection of the pHNF4Pr.luc reporter plasmid and the control plasmid pcDNA3 was 353. 


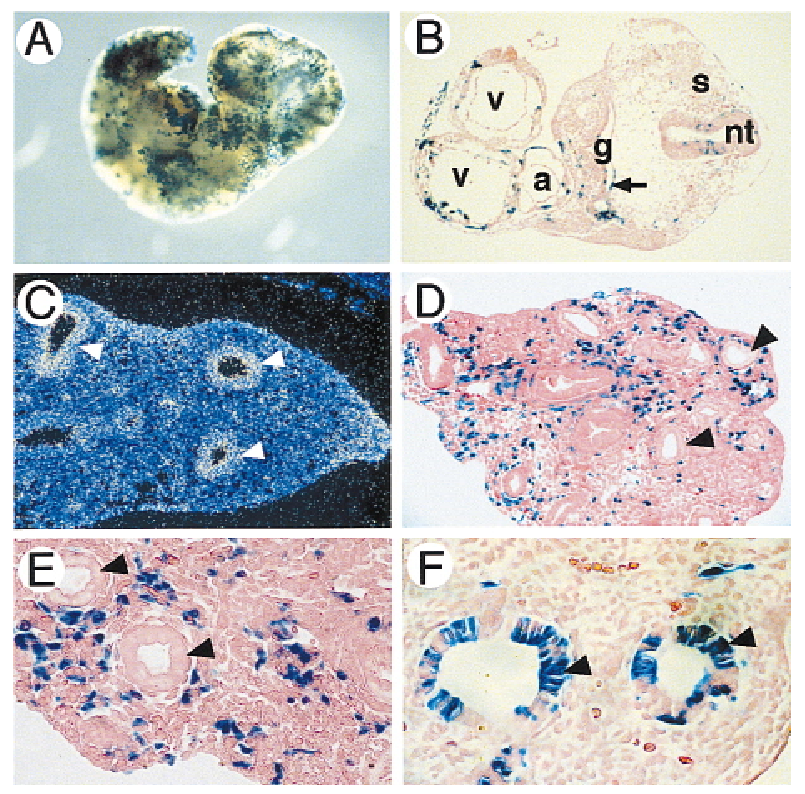

Figure 9. $\beta-g a l^{+}-\mathrm{GATA} 6^{-1-}$ ES cells fail to contribute to the embryonic bronchial epithelium of $\mathrm{GATA} 6^{-1-}-\mathrm{C} 57 \mathrm{BL} / 6$ chimeric embryos. (A) X-gal staining of an E10.5 GATA $^{-1-}$ C57BL/ 6 chimeric embryo. (B) Histological analysis of a section through the thoracic region of an E10.5 GATA $6^{-1-}$-C57BL/ 6 chimera. (v) Ventricular and (a) atrial chambers of the primitive heart, (nt) neural tube, (s) somites, (g) primitive foregut. Magnification, 10x (C) In situ hybridization of a section through the primitive lung bud of an E13.5 mouse embryo by use of a GATA6 antisense riboprobe. (Arrowheads) Bronchial epithelium. (D) Histological analysis of a section through the primitive lung bud of an E13.5 chimeric embryo. (Arrowheads) Bronchial epithelium. Magnification 10x (E) Same as D but magnification, 20x (F) Histological analysis of a section through the primitive lung bud of a control E13.5 GATA $6^{+/-}-\mathrm{C} 57 \mathrm{BL} / 6$ chimeric embryo. $\beta$-gal ${ }^{+}-$GATA $6^{H-}$ cells contribute to both the bronchial epithelium (arrowheads) and the lung mesenchyme. Magnification, 20x

derm differentiation, as Pem, a homeobox gene expressed in all extra-embryonic tissues, including endoderm, was expressed at comparable levels in GATA $6^{-1-}$ and wild-type embryos. Moreover, the down-regulation in early endodermal markers does not represent general ized growth retardation, as equivalent expression of the ectodermal markers, Otx2 and ENC1, were observed within the epiblast of GATA $6^{-1-}$ and wild-type E6.5 embryos. These data al so establish that GATA-6 is critical for survival of the early primitive streak embryo as lethality was observed within $\sim 12 \mathrm{hr}$ of the onset of GATA 6 gene expression.

The defect represents a specific block in endoderm differentiation, as opposed to endoderm specification, because (1) the primitive endoderm is recognized as early as E4.0, whereas the gene encoding GATA6 is not expressed until E6.5; (2) histological analyses of GATA6deficient embryos demonstrated cells phenotypically resembling VE and PE; and (3) the genes encoding Pem and
GATA4 (al beit at a reduced level) are expressed in the visceral and parietal endoderm of GATA6-deficient embryos. Therefore, GATA 6 and the primitive GATA factors end- 1 and SERPEN T / ABF share the capacity to activate genes encoding endoderm-specific proteins required for differentiation of this cell lineage (M acM orris et al. 1992; Stroeher et al. 1994; Rehorn et al. 1996). However, it remains to be determined whether GATA 6 (possibly in concert with GATA4 and/or GATA5) regulates specification of the primitive endoderm and/or any endodermally derived cell lineage.

HNF4 is a bona fide transcriptional target of GATA 6 in the visceral endoderm

Previous studies have reveal ed that HNF4 is required for the late stages of visceral endoderm formation and lies downstream, or in an alternate pathway, from GATA4 in a transcriptional cascade controlling differentiation of the visceral endoderm (Duncan et al. 1997). Embryoid bodies derived from HNF4 ${ }^{-1-}$ ES cells form a morphological endoderm and express early markers of the endoderm lineage, incl uding GATA4, A po-E, and vH nf-1, but do not express later markers of visceral endoderm including AFP, TTR, A po-AI, Apo-AIV, A po-B, RBP, and TFN (Duncan et al. 1997). Consistent with these findings, normal or upregulated expression of GATA-4 was observed in E8.5 HNF4-deficient embryos, whereas expression of the genes encoding AFP, TFN, A po-AI, A po$A I V$, and Apo-B was almost undetectable in these mutant embryos (Duncan et al. 1997). We have shown through both loss-of-function (analysis of GATA6 ${ }^{-1-}$ ES cells and GATA $^{-1-}$ embryos) and gain-of-function (transactivation of the HNF4 promoter by forced expression of GATA 6) experiments that HNF4 gene expression is regulated by GATA6. Of note, the absence of HNF4 and other markers of visceral endoderm in GATA6-deficient embryos was not observed in GATA4-deficient embryos (Kuo et al . 1997) demonstrating that HNF4 is differentially regulated by GATA 6 and GATA 4 in the visceral endoderm of early primitive streak embryos. Taken together, these data demonstrate that in the visceral endoderm of the advanced egg cylinder/early primitive streak embryo HNF4 is a bona fi de transcriptional target of GATA6.

\section{GATA6: a hierarchical model of visceral} endoderm formation

For many years it has been suggested that formation and differentiation of visceral endoderm is a multistep process (Duncan et al. 1997; Gardner et al. 1983). The data presented in this work are consistent with a hierarchical model and serve to place GATA 6 and HNF4 within the context of this model (Fig. 10). The absence of HNF4 gene expression in GATA 6 ${ }^{-1-}$ ES cells and GATA6-deficient embryos coupled with the finding that forced expression of GATA6 activates the HNF4 promoter, strongly suggests that GATA6 lies upstream, and regulates (directly or indirectly) the expression of HNF4 in 
the visceral endoderm at E6.5-E7.5. HNF4, in turn, is required to activate the expression of sets of genes encoding secreted proteins (and late markers of endoderm differentiation) including AFP, TTR, A po-AI, Apo-AIV, A po-B, RBP and TFN. M oreover, these data demonstrate that GATA6 is required to maintain basal levels of GATA4 gene expression in the late egg cylinder/early primitive streak embryo. Conversely, the finding that GATA6 is upregulated in GATA4-deficient embryos suggests that GATA4 may suppress expression of GATA 6 in some embryonic tissues (Kuo et al. 1997).

This model also aids in understanding the molecular basis of the lethality observed at E7.0 in GATA6-deficient embryos. Despite the fact that GATA 6 is expressed exclusively in the VE and PE at this devel opmental stage, widespread programmed cell death was observed within the embryonic ectoderm beginning at E6.5, 12-24 hr after the onset of expression of GATA 6 in wild-type mice (see Fig. 4). Cell death was also observed in the embryonic ectoderm of HN F4-deficient embryos beginning at E6.5 (Chen et al. 1994). These data suggest that the lethality observed in GATA6-deficient embryos may result solely from abnormal differentiation of the extraembryonic visceral endoderm, which, in turn, results in abnormal expression of one, or more, factor(s) required for survival and/or proliferation of the embryonic ectoderm. The severity of the phenotype exhibited in GATA6 null embryos, which uniformly die by E7.5, whereas HNF4-deficient embryos survive to E10.5, may be due to the fact that GATA 6 lies upstream of HNF4 and thereby controls alternative pathways regulating endoderm differentiation possibly including those activated directly or indirectly by GATA4.

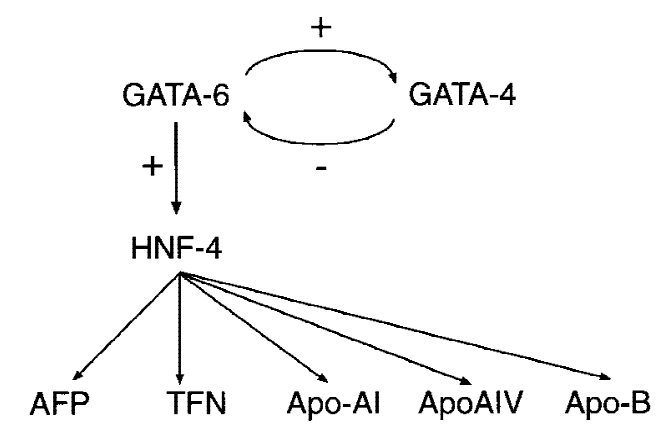

Figure 10. A transcriptional cascade controlling differentiation of the visceral endoderm. As described in Results and published previously (Duncan et al. 1997; Kuo et al. 1997), analysis of the phenotypes of GATA $6^{-1-}$, GATA $4^{-1-}$, and HNF4 $4^{-1-}$ mutant embryos has shown that GATA6 activates (directly or indirectly) the expression of the early endodermal marker HN F4, which in turn, activates the expression of late endodermal markers, including $\alpha$-fetoprotein (AFP), transferrin (TFN ), A poAl, A poAIV, and ApoB. In addition, GATA4 gene expression is down-regulated in GATA6-deficient embryos, whereas GATA6 gene expression is up-regulated in GATA4-deficient embryos suggesting cross-regulation between GATA 6 and GATA4.
GATA 6 and development of the endodermally derived bronchial epithelium

As the lung bud arises from the primitive foregut, GATA 6 is expressed at high level s within the embryonic bronchial epithelium serving to identify GATA6 as a candidate regulator of this endodermally derived cell lineage (M orrisey et al. 1996). Thus, it was noteworthy that GATA $6^{-1-}$ ES cells did not contribute to the embryonic bronchial epithelium, but did contribute to other endodermally derived cell lineages that coexpress GATA4, GATA5, and GATA 6 including the stomach epithelium and the small and large intestinal epithelium. This cellintrinsic defect was restricted to the bronchial epithelium, as lacZ-tagged GATA $6^{-1-}$ ES cells were observed throughout the pulmonary mesenchyme and other tissues. It is tempting to speculate that this cell-intrinsic defect may reflect the fact that GATA 6 is the only GATA factor expressed within the embryonic bronchial epithelium, effectively abrogating functional redundancies that may exist between members of the GATA4, GATA5, and GATA 6 subfamily el sewhere. In addition, these data demonstrate that GATA 6 may be required for the specification, survival and/or differentiation of the bronchial epithelium. Thus, it is noteworthy that the human surfactant protein $C$, rat surfactant protein $A$, and mouse CC10 promoters each contain embedded GATA motifs (Korfhagen et al. 1992; Ray et al. 1993; Wert et al. 1993). Identification of the bona fide transcriptional targets of GATA6 in the embryonic lung should provide fundamental insights into the transcriptional programs that control lung development.

\section{Materials and methods}

Plasmids

A genomic clone including the $5^{\prime}$ end of the murine GATA 6 gene was isolated from a SV129 mouse library by use of the full-length mouse GATA 6 cDNA as a probe (Morrisey et al. 1996). The targeting vector was generated in the pPNT plasmid (Tybulewicz et al. 1991), which contains the PGK-neo-poly(A) and PGK-tk-poly(A) cassettes for positive and negative selection, respectively. As schematically represented in Figure $1 \mathrm{~A}$, the pPN T G 6 targeting vector, contains the $4.5-\mathrm{kb}$ Notl (5' end)Xhol ( $3^{\prime}$ end) GATA6 genomic subfragment, which includes sequences in exon 3 through intron 3 subcl oned into $\mathrm{N}$ otl-Xholdigested pPNT, and the $2.5-\mathrm{kb} \mathrm{N}$ col-N col GATA 6 genomic subfragment subcloned into the BamHI site of pPNT. In pPNTG6, exons 4 and 5 encoding the amino- and carboxy-terminal zinc fingers, respectively, are replaced with the PGK-neo cassette. The pEF1/4F2.lacZ eukaryotic expression vector encoding the bacterial IacZ gene under the transcriptional control of the human $\mathrm{EF} 1 \alpha$ promoter and the murine 4F2 heavy chain enhancer has been described previously (Kuo et al. 1997). The pGEXG6 (amino acids 357-444) bacterial expression plasmid contains the mouse GATA 6 CDN A encoding the carboxy-terminal region of the protein (amino acids 357-444) into Sall-Xhol-digested pGEX4T3 (Pharmacia). The pCDNA3 control plasmid and the pCDNAG6 eukaryotic expression plasmid encoding the murine GATA 6 protein have been described previously (M orrisey et al . 1996). The pHNF4Pr.luc plasmid contains the 581-bp murine 
HNF4 promoter (T araviras et al. 1994) subcloned into the Xhol$\mathrm{Kpnl}$ sites of the pGL2-basic luciferase reporter plasmid.

Preparation of GATA6 polyclonal antiserum and Western blot analysis

The pGEXG6 (amino acids 357-444) plasmid was transformed into bacteria and glutathione S-transferase (GST)-GATA6 (amino acids 357-444) fusion protein was induced and purified from bacterial extracts as described previously (M orrisey et al. 1997). Rabbits were immunized with the purified GST-GATA6 (amino acids 357-444) fusion protein as per standard protocol of the Pocono Rabbit Farm and Laboratory (Canadensis, PA) for fusion proteins. Preimmune and immune IgG were isolated from the serum by protein A-Sepharose chromatography. Western blot analysis was performed with polyclonal antisera raised against the carboxyl terminus of the murine GATA 6 protein and in vitro translated murine GATA4, GATA5, and GATA6 protein, as described previously (M orrisey et al. 1997). A 48-kD band, corresponding to the expected size of GATA 6 protein, was identified with the GATA 6 polyclonal antisera, but not with preimmune serum (data not shown). This antisera did not recognize GATA4 or GATA5 protein (data not shown).

Generation of GATA $6^{+1-}$ and GATA $6^{-1-}$ ES cells and mice

The GATA 6 targeting construct was linearized with $\mathrm{Notl}$ and el ectroporated into RW ES cells as described previously (Soudais et al. 1995). After $24 \mathrm{hr}$, neomycin-resistant transfectants were selected in $250 \mu \mathrm{g} / \mathrm{ml} \mathrm{G} 418$ and $1 \mu \mathrm{m}$ gancyclovir for 8-10 days. DNA from resistant ES cell clones was analyzed by Southern blot analysis after BamHI digestion with a radiolabeled probe derived from genomic sequences located $3^{\prime}$ of the targeting vector (see Fig. 1A). GATA $6^{-1-}$ ES cells were obtained by subjecting independently derived GATA $6^{H-}$ clones to sel ection in G 418 at a concentration of $750 \mu \mathrm{g} / \mathrm{ml}$ as described previously (Soudais et al. 1995).

To generate GATA6-deficient mice, ES cells from four independently derived GATA $6^{+-}$clones were microinjected into C57BL/ 6 donor blastocysts that were implanted into pseudopregnant CD1 females (Bradley 1987; Hogan et al. 1994). The resulting male chimeras were mated with $\mathrm{C} 57 \mathrm{BL} / 6$ femal es and agouti offspring were genotyped by Southern blot analysis as described previously (Kuo et al. 1997). GATA6 $6^{+1}$ mice were then outbred with C57BL/ 6 and CD1 mice to generate heterozygous $\mathrm{GATA}^{+1-}$ mice that were interbred for phenotypic analysis. All animal experimentation was performed according to $\mathrm{N}$ ational Institutes of Health $(\mathrm{NIH})$ guidelines in the U niversity of Chicago Animal Care Facility.

Northern blot analyses of embryoid bodies derived from wild-type and GATA $6^{-1-}$ ES cells

ES cells were differentiated into embryoid bodies in suspension culture as described (D oetschman et al. 1985). Embryoid bodies were collected after $0,2,4,6,8$, and 12 days of liquid culture, RNA was isolated, and Northern blot analysis performed as described previously (Parmacek and Leiden 1989; Soudais et al . 1995). Probes included the mouse GATA6 cDNA (basepairs 1138-1450) (M orrisey et al. 1996) and the mouse GATA4 CDN A (basepairs 1678-1907). The mouse HNF4, mouse HNF3 $\beta$, and mouse AFP cDN A probes have been described previously (Kuo et al. 1997).
Generation of lacZ-tagged GATA $6^{-1-}$ ES cells and GATA $6^{-1-} /$ C57/BL-6 chimeric mice

The pEF1/4F2.lacZ expression vector was linearized with Bsal and electroporated into GATA $6^{+-}$and GATA $6^{-1-}$ ES cells as described previously (Kuo et al. 1997). At 8 day postselection in $175 \mu \mathrm{g} / \mathrm{ml}$ hygromycin, resistant col onies were stained for $\beta$-galactosi dase expression. Three independently derived GATA $6^{-1-}$ and GATA $6^{+-}$lacZ cell lines were microinjected into C57BL/ 6 blastocysts and implanted into pseudopregnant CD1 females as described (Bradley 1987). GATA $6^{+1-}$-C57BL/ 6 and GATA $6^{-1-}$ C57BL/ 6 chimeric embryos were microdissected from pregnant femal es and stained for $\beta$-gal actosi dase activity as described previously (Chang et al. 1995).

\section{Histological and in situ hybridization analysis}

Pregnant females from GATA $6^{+1-} \times \mathrm{GATA}^{+/-}$matings were anesthetized and perfused through the descending aorta with $4 \%$ paraformaldehyde in PBS to fix embryos in utero as described previously (Kuo et al. 1997). For electron microscopy, differentiated embryoid bodies were fixed in $2.5 \%$ gluteral dehyde in PBS, postfixed with $1 \%$ osmium tetraoxide, and stained with $1 \%$ uranyl acetate as described previously (Soudais et al. 1995). Electron micrographs were produced with a JEOL-CXII electron microscope. In situ hybridization with ${ }^{35}$ S-labeled CRN A probes was performed essentially as described by Eichele and coworkers (Kuratani et al. 1994). The cRN A probes used for in situ hybridizations were generated from the foll owing CDN A templates subcloned into pGEM $7 Z$ or pGEM 11Z; GATA6 (bp 1138-1450) (Morrisey et al. 1996), Otx2 (bp 212-509) (Simeone et al. 1992), EN C1 (bp 1412-1739) (Hernandez et al. 1997), Pem (bp 142-449) (Lin et al. 1994). The HNF4, HNF3 $\beta$, and GATA4 CRN A probes were generated as described previously Kuo et al. (1997). Histological sections and dark-field micrographs were made with a Zeiss Axiophot microscope.

\section{Transfections and luciferase assays}

$\mathrm{NIH}-3 \mathrm{~T} 3$ cells $\left(1 \times 10^{8}\right)$ were transfected with $2.5 \mu \mathrm{g}$ of luciferase reporter plasmid, between 0 and $25 \mu \mathrm{g}$ of the pcDNAG6 expression plasmid or the control pcDN A 3 plasmid, and $1 \mu \mathrm{g}$ of the pM SV $\beta$ gal reference plasmid with Lipofectin Reagent as described previously (Ip et al. 1994). Of note, in these experiments the total amount of plasmid DNA transfected was held constant. Forty-eight hours foll owing transfection, cell lysates were prepared and normalized for protein content by a commercially available kit (Bio-Rad, Hercules, CA). Luciferase and $\beta$-galactosi dase assays were performed as described previously (Solway et al. 1995). All experiments were repeated at least three times to ensure reproducibility. Luciferase activities were corrected for variations in transfection efficiencies as determined by assaying cell extracts for $\beta$-galactosidase activities.

\section{TUNEL analysis}

Embryos for TUNEL assays were fixed, embedded, and sectioned in the same manner as for the in situ hybridization studies. TUNEL reaction to detect incorporation of biotinylated dUTP mediated by terminal deoxytransferase was performed as described on sections of E6.5 and E7.0 mouse GATA $6^{++}$and GATA6 $^{-1-}$ embryos (Gavrieli et al. 1992).

\section{Acknowledgments}

We thank Jeffrey M. Leiden and Chay Kuo for providing the 
murine HNF4 and HNF3 3 CDNA probes that were used for $\mathrm{N}$ orthern blot and in situ hybridization analysis. We thank Lisa Gottschalk for expert preparation of the figures and Amy M urphy for secretarial assistance. Wethank Jon Epstein and Clayton Buck for reviewing the manuscript and hel pful comments. This work was supported by NIH grant HL51145 to M.S.P. M.S.P is an Established Investigator of the American Heart Association.

The publication costs of this article were defrayed in part by payment of page charges. This article must therefore be hereby marked 'advertisement' in accordance with 18 USC section 1734 solely to indicate this fact.

\section{References}

Arceci, R.J., A.A. King, M.C. Simon, S.H. Orkin, and D.B. Wilson. 1993. M ouse GATA-4: A retinoic acid-inducibleGATAbinding transcription factor expressed in endodermally derived tissues and heart. Mol. Cell. Biol. 13: 2235-2246.

Bradley, A. 1987. Production and analysis of chimeric mice. In Teratocarcinomas and embryonic stem cells, a practical approach (ed. E.J. Robertson), pp. 113-151. IRL Press, Oxford, UK.

Chang, M.W., E. Barr, J. Seltzer, Y.-Q. Jiang, G.J. N abel, E.G. N abel, M.S. Parmacek, and J.M. Leiden. 1995. Cytostatic gene therapy for vascular proliferative disorders with a constitutively active form of the retinoblastoma gene product. Science 267: 518-522.

Chen, W.S., K. Manova, D.C. Weinstein, S.A. Duncan, A.S. Plump, V.R. Prezioso, R.F. Bachvarova, and J.E. Darnell. 1994. Disruption of the HNF-4 gene, expressed in visceral endoderm, leads to cell death in embryonic ectoderm and impaired gastrulation of mouse embryos. Genes \& Dev. 8: 2466-2477.

Doetschman, T.C., H. Eistetter, M. Katz, W. Schmidt, and R. Kemler. 1985. The in vitro development of blastocyst-derived embryonic stem cell lines: Formation of visceral yolk sac, blood islands and myocardium. J. Embryol. Exp. Morphol. 87: 27-45.

Dorfman, D.M., D.B. Wilson, G.A. Bruns, and S.H. Orkin. 1992. Human transcription factor GATA-2. Evidence for regulation of preproendothelin-1 gene expression in endothelial cells. J. Biol. Chem. 267: 1279-1285.

Duncan, S.A., K. Manova, W.S. Chen, P. Hoodless, D.C. Weinstein, R.F. Bachvarova, and J.E. Darnell. 1994. Expression of transcription factor HNF-4 in extraembryonic endoderm, gut, and nephrogenic tissue of the developing mouse embryo: HNF-4 is a marker for primary endoderm in the implanting blastocyst. Proc. Natl. Acad. Sci. 91: 7598-7602.

Duncan, S.A., A. N agy, and W. Chan. 1997. M urine gastrulation requires $\mathrm{HN}$ F-4 regulated gene expression in the visceral endoderm: Tetraploid rescue of Hnf-4( $-1-$ embryos. Development 124: 279-287.

Evans, T. and G. Felsenfeld. 1988. An erythrocyte-specific DNA-binding factor recognizes a regulatory sequence common to all chicken globin genes. Proc. Natl. Acad. Sci. 85: 5976-5980.

Gardner, R.L. 1982. Investigation of cell lineage and differentiation in the extraembryonic endoderm of the mouse embryo. J. Embryol. Exp. Morphol. 68: 175-198.

-_-. 1983. Origin and differentiation of extraembryonic tissues in the mouse. Int. Rev. Exp. Pathol. 24: 63-133.

Gavrieli, Y., Y. Sherman, and S.A. Ben-Sasson. 1992. Identification of programmed cell death in situ via specific labeling of nuclear DN A fragmentation. J. Cell Biol. 119: 493-501.

Hernandez, M .-C., P.J. Andres-Barquin, S. M artinez, A. Bulfone,
J.L.R. Rubenstein, and M.A. Israel. 1997. EN C-1: A novel mammalian Kelch-related gene specifically expressed in the nervous system encodes an actin-binding protein. J. Neurosci. 17: 3038-3051.

Ho, I.C., P. Vorhees, N. Marin, B.K. Oakley, S.F. Tsai, S.H. Orkin, and J.M. Leiden. 1991. Human GATA-3: A lineage-restricted transcription factor that regulates the expression of the T cell receptor al pha gene. EMBO J. 10: 1187-1192.

Hogan, B., R. Beddington, F. Constantini, and E. Lacy. 1994. Manipulating the mouse embryo. Cold Spring Harbor Laboratory Press, Cold Spring Harbor, NY.

Hogan, B.L.M., D.P. Barlow, and R. Tilly. 1983. F9 teratocarcinoma cells as a model for the differentiation of parietal and visceral endoderm in the mouse embryo. Cancer Surv. 2: 115-140.

Ip, H.S., D.B. Wilson, M. Heikinheimo, Z. Tang, C.N. Ting, M.C. Simon, J.M. Leiden, and M.S. Parmacek. 1994. The GATA-4 transcription factor transactivates the cardiac muscle-specific troponin C promoter in nonmuscle cells. Mol. Cell Biol. 14: 7517-7526.

Kelley, C., H. Blumberg, L.I. Zon, and T. Evans. 1993. GATA-4 is a novel transcription factor expressed in endocardium of the devel oping heart. Devel opment 118: 817-827.

Korfhagen, T.R., M.D. Bruno, S.W. Glasser, P.J. Ciraolo, J.A. Whitsett, D.L. Lattier, K.A. Wikenheiser, and J.C. Clark. 1992. Murine pulmonary surfactant SP-A gene: Cloning, sequence, and transcriptional activity. Am. J. Physiol. 263: L546-L554.

Kuo, C.T., E.E. Morrisey, R. Anandappa, K. Sigrist, M.M. Lu, M.S. Parmacek, C. Soudais, and J.M. Leiden. 1997. GATA-4 transcription factor is required for ventral morphogenesis and heart tube formation. Genes \& Dev. 11: 1048-1060.

Kuratani, S., J.F. Martin, S. Wawersik, B. Lilly, G. Eichele, and E.N. Olson. 1994. The expression pattern of the chick homeobox gene gM Hox suggests a role in patterning of the limbs and face and in compartmental ization of somites. Dev. Biol. 161: 357-369.

Lai , E., K.L. Clark, S.K. Burley, and J.E. Darnell. 1993. Hepatocyte nuclear factor $3 /$ fork head or 'winged helix' proteins: A family of transcription factors of diverse biologic function. Proc. Natl. Acad. Sci. 90: 10421-10423.

Laverriere, A.C., C. MacN eill, C. Mueller, R.E. Poelmann, J.B. Burch, and T. Evans. 1994. GATA-4/5/6, a subfamily of three transcription factors transcribed in developing heart and gut. J. Biol. Chem. 269: 23177-23184.

Lin, T.P., P.A. Labosky, L.B. Grabel, C.A. Kozak, J.L. Pitman, J. Kleeman, and C.L. M acLeod. 1994. The Pem homeobox gene is X-linked and exclusively expressed in extraembryonic tissues during mouse development. Dev. Biol. 166: 170-179.

M acM orris, M., S. Broverman, S. Greenspoon, K. Lea, C. Madei, T. Blumenthal, and J. Spieth. 1992. Regulation of vitellogenin gene expression in transgenic Caenorhabditis el egans: Short sequences required for activation of the vit-1 promoter. Mol. Cell. Biol. 12: 1652-1662.

Molkentin, J.D., Q. Lin, S.A. Duncan, and E.N. Olson. 1997. Requirement of the transcription factor GATA4 for heart tube formation and ventral morphogenesis. Genes \& Dev. 11: 1061-1072.

Morrisey, E.E., H.S. Ip, M.M. Lu, and M.S. Parmacek. 1996. GATA-6: A zinc finger transcription factor that is expressed in multiple cell lineages derived from lateral mesoderm. Dev. Biol. 177: 309-322.

Morrisey, E.E., H.S. Ip, Z. Tang, M.M. Lu, and M.S. Parmacek. 1997. GATA-5: A transcriptional activator expressed in a novel temporally and spatially-restricted pattern during embryonic development. Dev. Biol. 183: 21-36. 
M ortensen, R.M., D.A. Conner, S. Chao, A.A.T. Geisterfer-Lowrance, and J.G. Seidman. 1992. Production of homozygous mutant ES cells with a single targeting construct. Mol. Cell Biol. 12: 2391-2395.

Orkin, S.H. 1992. GATA-binding transcription factors in hematopoietic cells. Blood 80: 575-581.

Parmacek, M.S. and J.M. Leiden. 1989. Structure and expression of the murine slow/cardiac troponin C gene. J. Biol. Chem. 264: 13217-13225.

Ray, M.K., S. Magdaleno, B.W. O'Malley, and F.J. DeMayo. 1993. Cloning and characterization of the mouse Clara Cell specific $10 \mathrm{kD}$ protein gene: Comparison of the $5^{\prime}$ flanking region with the human rat and rabbit gene. Biochem. Biophys. Res. Commun. 197: 163-171.

Rehorn, J.R., H. Thelen, A.M. Michelson, and R. Reuter. 1996. A molecular aspect of hematopoiesis and endoderm development common to vertebrates and Drosophila. Development 120: 1123-1135.

Reuter, R. 1994. The gene serpent has homeotic properties and specifies endoderm versus ectoderm within the Drosophila gut. Development 120: 1123-1135.

Sasaki, H. and B.L.M. Hogan. 1994. HNF-3 $\beta$ as a regulator of floor plate development. Cell 76: 103-115.

Simeone, A., D. A campora, M. Gulisano, A. Stornaiuolo, and E. Boncinelli. 1992. Nested expression domains of four homeobox genes in developing rostral brain. Nature 358: 687690.

Simon, M.C. 1995. Gotta have GATA. Nat. Genet. 11: 9-11.

Sladek, F.M., W. Zhong, E. Lai, and J.E. Darnell. 1990. Liver enriched transcription factor HNF-4 is a novel member of the steroid hormone receptor superfamily. Genes \& Dev. 4: 2353-2365.

Solway, J., J. Seltzer, F.F. Samaha, S. Kim, L.E. Alger, Q. Niu, E.E. Morrisey, H.S. Ip and M.S. Parmacek. 1995. Structure and expression of a smooth muscle cell-specific gene, SM 22 $\alpha$. J. Biol. Chem. 270: 13460-13469.

Soudais, C., M. Bielinska, M. Heikinheimo, C.A. MacArthur, N. N arita, J.E. Saffitz, M.C. Simon, J.M. Leiden, and D.B. Wilson. 1995. Targeted mutagenesis of the transcription factor GATA-4 gene in mouse embryonic stem cells disrupts visceral endoderm differentiation. Development 121:38773888.

Stroeher, V.L., B.P. Kennedy, K.I. Millen, D.F. Schroeder, M.G. Hawkins, B. Goszczynski, and J.D. McGhee. 1994. DNAprotein interactions in the Caenorhabditis el egans embryo: Oocyte and embryonic factors that bind to the promoter of the gut-specific ges-1 gene. Dev. Biol. 163: 367-380.

Tam, P.P.L. and R.S.P. Beddington. 1992. Establishment and organization of germ layers in the gastrulating mouse embryo. Ciba Found. Symp. 165: 27-41.

Taraviras, S., A.P. M onaghan, G. Schutz, and G. Kelsey. 1994. Characterization of the mouse HNF-4 gene and its expression during mouse embryogenesis. Mech. Dev. 48: 67-79.

Tsai, S.F., D.I.K. Martin, L.I. Zon, A.D. D'Andrea, G.G. Wong, and S.H. Orkin. 1989. Cloning of CDNA for the major DNAbinding protein of the erythroid lineage through expression in mammalian cells. Nature 339: 446-451.

Tybulewicz, V.L.J., C.E. Crawford, P.K. Jackson, R.T. Bronson, and R.C. Mulligan. 1991. N eonatal lethality and lymphopenia in mice with a homozygous disruption of the c-abl protooncogene. Cell 65: 1153-1163.

Weinstein, D.E., A.R. Altaba, W.S. Chen, P. Hoodless, V.R. Prezioso, T.M. Jessel, and J.E. Darnell. 1994. The winged helix transcription factor HN F3 $\beta$ is required for notochord development in the mouse embryo. Cell 78: 575-588.

Weiss, M.J. and S.H. Orkin. 1995. GATA transcription factors:
Key regulators of hematopoiesis. Exp. Hematol. 23: 99-107.

Wert, S.E., S.W. Glasser, T.R. Korfhagen, and J.A. Whitsett. 1993. Transcriptional el ements from the human SP-C gene direct expression in the primordial respiratory epithelium of transgenic mice. Dev. Biol. 156: 426-443.

Wilson, D.B., D.M. Dorfman, and S.H. Orkin. 1990. A nonerythroid GATA-binding protein is required for function of the human preproendothelin-1 promoter in endothelial cells. Mol. Cell. Biol. 10: 4854-4862.

Zhu, J., R.J. Hill, P.J. Heid, M. Fukuyama, A. Sugimoto, J.R. Priess, and J.H. Rothman. 1997. end-1 encodes an apparent GATA factor that specifies the endoderm precursor in Caenorhabditis el egans embryos. Genes \& Dev. 11: 2883-2896. 


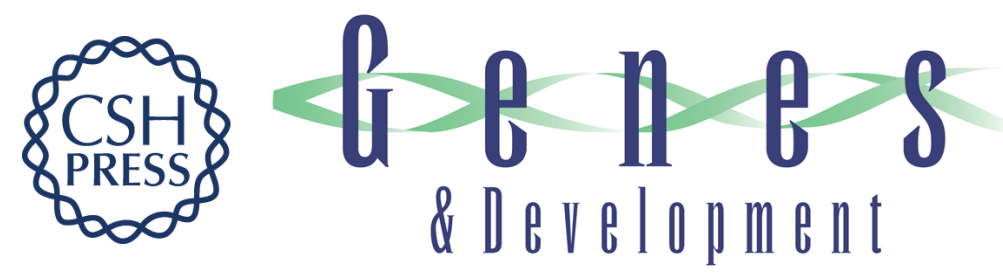

\section{GATA6 regulates HNF4 and is required for differentiation of visceral endoderm in the mouse embryo}

Edward E. Morrisey, Zhihua Tang, Kirsten Sigrist, et al.

Genes Dev. 1998, 12:

Access the most recent version at doi:10.1101/gad.12.22.3579

References

This article cites 46 articles, 25 of which can be accessed free at: http://genesdev.cshlp.org/content/12/22/3579.full.html\#ref-list-1

\section{License}

Email Alerting

Receive free email alerts when new articles cite this article - sign up in the box at the top Service right corner of the article or click here.

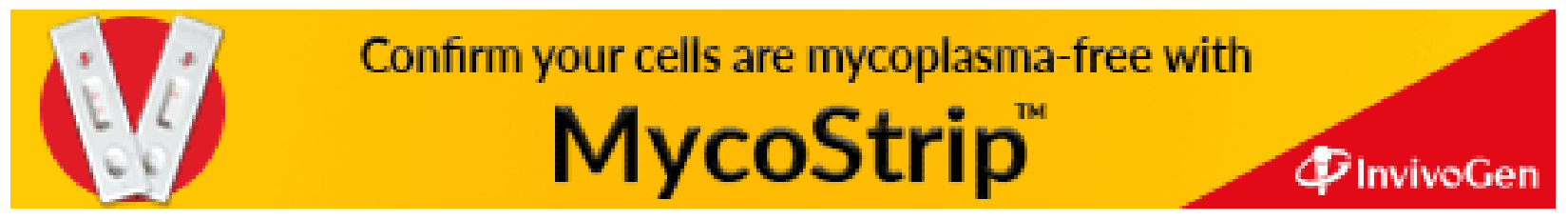

